\title{
OS DISTRITOS EM GOIÁS: DEFINIÇÕES OFICIAIS E APONTAMENTOS TEÓRICOS
}

\author{
DISTRICT IN GOIÁS: OFFICIAL DEFINITIONS AND THEORETICAL POINTS
}

\section{LOS DISTRITOS EN GOIÁS: DEFINICIONES OFICIALES Y NOTAS TEÓRICAS}

\author{
Dallys Dantas de Souza - Secretaria Municipal de Educação - Aparecida de Goiânia - Goiás - Brasil \\ dallysdantas@gmail.com
}

Denis Castilho - Universidade Federal de Goiás - Goiânia - Goiás - Brasil

deniscastilho@hotmail.com

\section{Resumo}

No Brasil, os distritos municipais são concebidos como unidades territoriais legalmente instituídas para fins administrativos. Atualmente o território goiano possui 71 distritos distribuídos em 45 municípios. Compreender o sentido territorial desses lugares a partir de definições oficiais e de aproximações teóricas é o objetivo deste trabalho. Para tanto, analisamos a legislação pertinente e, a partir da mensuração de dados secundários, apresentamos o panorama demográfico e a espacialização desses distritos em Goiás. Também analisamos as vilas, bem como características peculiares desses núcleos, a exemplo do cotidiano, serviços e inserção na rede urbana.

Palavras-chaves: distrito, vila, unidade territorial.

\section{Abstract}

In Brazil, municipal districts are designed as legally aimed for administrative purposes. Goiás currently has 71 districts spread in 45 municipalities. This paper aims to understand the territorial sense of these places from official definitions and theoretical approaches. So, we analyzed the relevant legislation and, from the secondary data measurement, we presented a spatial and demographic landscape of these districts in Goiás. We also analyzed villages and their peculiar features, like day by day activities, services, and involvement in urban network.

Key words: district, village, territorial unit.

\section{Resumen}

En Brasil, los distritos están diseñados como unidades territoriales legalmente instituidos para fines administrativos. Goiás tiene actualmente 71 distritos repartidos en 45 municipios. Comprender el sentido territorial de estos lugares desde definiciones oficiales y de enfoques teóricos es el objetivo de este trabajo. Por lo tanto, se analiza la legislación pertinente y, a partir de la interpretación de los datos secundarios, se presenta el perfil demográfico y la espacialización de estos distritos en Goiás. También analizamos los pueblos, así como características peculiares de estos núcleos, como la vida cotidiana de las personas, los servicios y la inserción en la red urbana.

Palabras clave: distrito, pueblo, unidad territorial.

\section{Introdução}

Os distritos são definidos como unidades territoriais legalmente instituídas para fins administrativos. Há no Brasil quase o dobro de 
distritos, se comparado ao número de municípios. São 10.283 unidades distritais para 5.563 entes municipais (IBGE, 2011). Isso ocorre porque a cidade sede localiza-se em área considerada como distrito primário. Os distritos secundários, por outro lado, são aqueles que têm a vila como sede distrital. Mas por questões didáticas e pelo fato de ser incomum referir-se aos municípios como distritos primários, os distritos secundários serão aqui, doravante, mencionados apenas como distritos.

Em Goiás, dos 246 municípios, 45 encontram-se subdivididos em 71 distritos. Dois deles fogem à regra dos demais, por se localizarem em regiões metropolitanas, apresentarem um histórico de rápida expansão urbana e, consequentemente, por possuírem um alto contingente populacional: Nova Brasília, que fica no município de Aparecida de Goiânia e Jardim Ingá, em Luziânia, que possuem, pela ordem, 298.002 e 64.547 habitantes (IBGE, 2011). O restante dos distritos goianos possui população muito abaixo dessa marca, até porque a grande maioria deles conta com menos de mil habitantes. Alguns núcleos, os quais recebem a denominação de vila, em função de ser a sede distrital, mais se parecem com lugarejos, dados a incipiente população e o pequeno número de residências. Apesar disso, também existem vilas que se assemelham a muitas cidades pequenas, tendo em vista a infraestrutura do núcleo e a densidade populacional do distrito.

Compreender a realidade territorial desses lugares, a partir de definições oficiais e de apontamentos teóricos, é o objetivo deste trabalho. Para tanto, analisamos definições do vocábulo distrito em dicionários, decretos e instituições, como o Instituto Brasileiro de Geografia e Estatística (IBGE). A polissemia do termo também demandou uma discussão teórica. Além disso, procedemos levantamento e análise de dados secundários relativos à população, à sua distribuição espacial, assim como às características peculiares das vilas, a exemplo do cotidiano, dos serviços e da inserção na rede urbana.

Distrito: uma primeira aproximação

Distrito é um vocábulo relativamente utilizado em nossa linguagem cotidiana. Sua acepção, porém, ainda é pouco esclarecida, pois varia em função do contexto em que é aplicada. Também há, na maioria dos casos, uma incerteza semântica quando pronunciamos, ouvimos e/ou lemos o 
termo. O Dicionário Houaiss da Língua Portuguesa apresenta a seguinte definição: "Divisão administrativa de um município ou cidade" (Houaiss; Villar, 2008, p. 257). Por esse ponto de vista, distrito é basicamente uma divisão administrativa ou judicial do município. No entanto, embora sua definição esteja sobremaneira ligada a essa ideia, distrito pode representar outras acepções.

De modo geral, no Brasil, o termo distrito designa áreas de extensões e limites predefinidos, sob a administração de autoridades cujos poderes variam de natureza, que pode ser tanto pública quanto particular. Existem, por exemplo, os distritos judiciários que têm como sede os cartórios; os distritos policiais cujas sedes são as delegacias; os distritos sanitários, os distritos industriais e assim por diante. No Brasil, o distrito dotado de natureza político-administrativa ocorre tanto no âmbito da União quanto dos estados e municípios. O país conta atualmente com um Distrito Federal, ${ }^{1}$ um Distrito Estadual ${ }^{2}$ e 10.283 distritos municipais (IBGE, 2011). É neste último nível administrativo, portanto, que se inscrevem as unidades que estão sendo analisadas neste trabalho.

O número de distritos municipais, conforme acabamos de apresentar, é quase duas vezes maior que a quantidade de municípios brasileiros, atualmente na ordem de 5.563 (IBGE, 2011). Isso ocorre porque um município pode ser subdividido em mais de um distrito. Quando da ocorrência dessa subdivisão, os distritos são classificados em primários e secundários. A primeira classificação refere-se ao chamado distrito sede, cujo núcleo urbano sedia o governo municipal e, portanto, recebe a categoria de cidade. Por sua vez, o secundário é o chamado distrito não sede, em que o núcleo urbano (geralmente formado por um povoado ou lugarejo) recebe a categoria de vila. Logo, a cidade está para o município assim como a vila para o distrito. Essa definição de cidade e vila como sedes de município e distrito, respectivamente, é dada pelo Decreto-Lei $\mathrm{n}^{0} 311$, de 2 de março de 1938. O texto normativo assim diz:

Art. $2^{\circ}$ - Os municípios compreenderão um ou mais distritos, formando área contínua. [...] Art. $3^{\circ}$ A sede do município tem a categoria de cidade e lhe dá o nome. Art. $4^{\circ} \mathrm{O}$ distrito se designará pelo nome da respectiva sede, a qual, enquanto não for erigida em cidade, terá a categoria de vila. Parágrafo único. No mesmo distrito não haverá mais de uma vila. (Brasil, 1938) 
No artigo 10 desse mesmo Decreto, também é dito que "não haverá, no mesmo Estado, mais de uma cidade ou vila com a mesma denominação". Esse Decreto-Lei, que ficou conhecido como "Lei Geográfica do Estado Novo" e vigora até hoje, foi criado com o objetivo de "resolver definitivamente os limites do território nacional no tocante à delimitação uniforme das circunscrições territoriais nos âmbitos municipais e distritais", assinala Penha (1993, p. 114).

Como já ressaltado, os distritos primários são aqui inscritos como municípios, e os secundários, apenas como distritos. O fato é que, apesar de importante, essa significação semântica de distrito é elementar. Vejamos, nesse sentido, algumas definições oficiais. De acordo com o IBGE (2011), distrito é uma unidade administrativa do município e

sua criação, desmembramento ou fusão depende de leis municipais, que devem observar a continuidade territorial e os requisitos previstos em lei complementar estadual. Podem ser subdivididos em unidades administrativas denominadas subdistritos, regiões administrativas, zonas ou outra denominação específica. (p. 21)

Entretanto, se a criação de distritos "depende de leis municipais", o mesmo não acontecia antes da Constituição de 1988, quando muitos distritos brasileiros foram criados por meio de legislação estadual. É o caso de distritos goianos como São João ${ }^{3}$ (município de Goiás), Goialândia $^{4}$ (município de Anápolis) e Jacilândia ${ }^{5}$ (município de Itapirapuã). Para explicar essa situação, devemos considerar o contexto jurídico-político estadual do período de criação desses e de outros distritos, a saber, as décadas de 1960 e 1970, quando vigorava no estado de Goiás a Constituição promulgada em 13 de maio de 1967. A Carta Constitucional previa, entre outros aspectos, a regulação territorial dos municípios como competência do Estado, por meio da legislatura estadual. Assim dispunha o seu Art. 15:

À Assembléia Legislativa, com a sanção do Governador, cabe dispor, mediante lei, sôbre tôdas as matérias de competência do Estado, especialmente sôbre: (...) XX - assuntos municipais, respeitados o principio constitucional da autonomia dos Municípios e os preceitos desta Constituição, e particularmente sôbre; a) - criação e supressão de Municípios; divisão em distritos; limites territoriais. (Goiás, 2014a) 
A Carta Estadual ainda reiterava, em seu Art. 89, que a criação de municípios, bem como a sua divisão em distritos, dependia de lei estadual. O texto constitucional determinava, portanto, que ao Estado competia legislar sobre a divisão territorial dos municípios em distritos. Mesmo com a Emenda n ${ }^{\circ}$ 1, de 7 de julho de 1970, à Carta Estadual de 1967, essa competência especial não se alterou. Tanto é verdade que o texto constitucional passou a vigorar com a seguinte redação:

Art. 15 - À Assembléia Legislativa, com a sanção do Governador, cabe dispor, mediante lei, sôbre tôdas as matérias de competência do Estado, especialmente: [...] XVII - Municípios: criação e supressão; divisão em distritos; limites territoriais; diretrizes da vida política e administrativa; normas de direito financeiro, de fiscalização financeira e orçamentária e de prestação de contas da administração. (Goiás, 2014c)

A situação foi alterada somente a partir da promulgação da Constituição Federal em 5 de outubro de 1988. Atendendo aos dispositivos dessa Constituição, uma nova Carta Estadual foi elaborada em 1989. De acordo com o novo texto constitucional, em seu Art. $4^{\circ}$,

compete ao Estado, sem prejuízo de outras competências que exerça isoladamente ou em comum com a União ou com os Municípios: I - legislar sobre assuntos de seu interesse e, especialmente, sobre: (...) b) criação, incorporação, fusão e desmembramento de Municípios, dentro do período determinado por lei complementar federal, e estabelecimento de critérios para a criação de distritos administração. (Goiás, 2014c)

Nessa Carta, portanto, a competência do Estado é a de estabelecer "critérios para a criação de distritos”, e não mais de criá-los. Essa competência passa a ser dos Municípios. Assim, o seu Art. 64 define: "Compete aos Municípios: (...) XIII - criar, organizar e suprimir distritos, observada a legislação complementar estadual e garantida a participação popular”. ${ }^{6}$ É importante ressaltar esses pontos porque, do mesmo modo que em Goiás, essas alterações nas cartas constitucionais, no que diz respeito aos distritos, ocorreram em todo território nacional, o que justifica a relevância da definição do IBGE sobre as subdivisões territoriais. Vejamos, portanto, um pouco mais sobre a realidade populacional e a espacialização dos distritos em Goiás. 


\section{Os distritos em Goiás}

Goiás possui 71 distritos localizados em 45 municípios. Na grande maioria dos casos, esses distritos têm como característica fundamental a presença de pelo menos um aglomerado "urbano" que recebe a categoria de vila. Mas além da área instituída como urbana, os distritos também possuem área rural, como será visto na Tabela mais adiante, referente à população urbana e rural em todos os distritos goianos. Convém ressaltar, no entanto, que além desses distritos, Goiás possui uma grande quantidade (e diversidade) de pequenos aglomerados espalhados por todo seu território, desde os mais elementares, a exemplo dos lugarejos, até aqueles que possuem oferta de bens e serviços básicos, como é o caso dos povoados. $^{7}$ Estes são definidos pelo IBGE (2010, p. 32) como localidade que possui pelo menos

um (1) estabelecimento comercial de bens de consumo frequente e dois (2) dos seguintes serviços ou equipamento: um (1) estabelecimento de ensino fundamental, do 10 ao 90 ano, em funcionamento regular; um (1) posto de saúde, com atendimento regular e um (1) templo religioso de qualquer credo, para atender aos moradores de aglomerados e/ou áreas rurais próximas.

Ambos, povoado e lugarejo, são de caráter coletivo e, portanto, não estão vinculados a um único proprietário do solo. A diferença entre um e outro está no fato de o lugarejo não dispor dos serviços ou equipamentos enunciados para o povoado, tal como definido pelo IBGE (2010). Quando um distrito é criado (atualmente por lei municipal), a localidade que se torna a sede desse distrito (pode ser um povoado ou, em alguns casos, o lugarejo) recebe a categoria de vila. Esta, portanto, como sede distrital, recebe o mesmo nome do distrito a que pertence. É mais comum a criação dessas unidades administrativas onde exista aglomerado com serviços públicos básicos, a exemplo de um posto de saúde, escola, posto policial, além de um cartório de registro civil. Alguns municípios, no entanto, criam distritos em áreas destituídas desses serviços.

Importante ressaltar que, embora em um distrito possa haver mais de um povoado ou lugarejo, haverá apenas uma vila, ou seja, somente uma sede. É o que determina o Decreto-Lei no 311 (a "Lei Geográfica”), de 1938, em seu Art. $4^{\circ}$. Os dados populacionais por tipo de residência do censo de 2010 de todos os distritos goianos revelam o quanto são diver- 
sificados. A Tabela a seguir permite observar pelo menos três situações interessantes no que tange à diversidade populacional desses distritos. A primeira é o fato de alguns possuírem população maior que alguns municípios emancipados. Distritos como Interlândia (município de Anápolis) e Bezerra (município de Formosa), com população de 1.961 habitantes e 2.788 habitantes, respectivamente, possuem população superior aos municípios de Anhanguera (1.020 habitantes), Lagoa Santa (1.254), Cachoeira de Goiás (1.417), São João da Paraúna (1.689) e Moiporá (1.763). Este último, aliás, também possui distrito, indicando outra situação curiosa: a de que há município com população abaixo de três mil habitantes que possui distrito. No caso de Moiporá, dos 1.763 habitantes, 470 residem no distrito de Messianópolis. Outro exemplo é o município de Ivolândia, que possui uma população total de 2.663 habitantes, dos quais 559 residem no distrito de Campolândia (IBGE, 2011).

Tabela - População por tipo de residência dos distritos goianos (2010)

\begin{tabular}{|c|c|c|c|c|c|c|c|}
\hline \multirow[t]{2}{*}{ Município } & \multirow[t]{2}{*}{ Distrito } & \multicolumn{2}{|c|}{$\begin{array}{l}\text { População do } \\
\text { distrito }\end{array}$} & \multirow[t]{2}{*}{ Município } & \multirow[t]{2}{*}{ Distrito } & \multicolumn{2}{|c|}{$\begin{array}{l}\text { População do } \\
\text { distrito }\end{array}$} \\
\hline & & Urbana & Rural & & & Urbana & Rural \\
\hline $\begin{array}{l}\text { Alto Paraíso } \\
\text { de Goiás }\end{array}$ & São Jorge & 446 & 59 & Itarumã & Olaria do Angico & 24 & 490 \\
\hline \multirow{4}{*}{ Anápolis } & Goialândia & 832 & 173 & Ivolândia & Campolândia & 98 & 461 \\
\hline & Interlândia & 1355 & 606 & \multirow[b]{3}{*}{ Jussara } & Canadá & 11 & 516 \\
\hline & Joanápolis & 457 & 442 & & Juscelândia & - & 88 \\
\hline & Sousânia & 528 & 949 & & $\begin{array}{l}\text { São Seb.do Rio } \\
\text { Claro }\end{array}$ & 179 & 894 \\
\hline \multirow{2}{*}{ Anicuns } & Capelinha & 308 & 287 & Luziânia & Jardim Ingá & 64547 & - \\
\hline & Choupana & 273 & 154 & Matrinchã & Lua Nova & 565 & 538 \\
\hline $\begin{array}{l}\text { Ap. de } \\
\text { Goiânia }\end{array}$ & Nova Brasília & 297897 & 105 & Minaçu & Cana Brava & 463 & 3066 \\
\hline Campinorte & Colinaçu & 418 & 931 & Moiporá & Messianópolis & 313 & 157 \\
\hline Catalão & $\begin{array}{l}\text { Sto. Antônio do } \\
\text { Rio Verde }\end{array}$ & 2018 & 1295 & \multirow{4}{*}{$\begin{array}{l}\text { Montes Claros } \\
\text { de Goiás }\end{array}$} & Ap. do Rio Claro & 328 & 126 \\
\hline $\begin{array}{l}\text { Colinas do } \\
\text { Sul }\end{array}$ & Vila Borba & 344 & 246 & & Lucilândia & 140 & 268 \\
\hline Cristalina & Campos Lindos & 6290 & 1942 & & \begin{tabular}{|l|}
$\begin{array}{l}\text { Ponte Alta do } \\
\text { Araguaia }\end{array}$ \\
\end{tabular} & 647 & 621 \\
\hline Crixás & Auriverde & 410 & 1260 & & $\begin{array}{l}\text { Registro do } \\
\text { Araguaia }\end{array}$ & 143 & 604 \\
\hline
\end{tabular}




\begin{tabular}{|c|c|c|c|c|c|c|c|}
\hline \multirow[t]{2}{*}{ Município } & \multirow[t]{2}{*}{ Distrito } & \multicolumn{2}{|c|}{$\begin{array}{l}\text { População do } \\
\text { distrito }\end{array}$} & \multirow[t]{2}{*}{ Município } & \multirow[t]{2}{*}{ Distrito } & \multicolumn{2}{|c|}{$\begin{array}{c}\text { População do } \\
\text { distrito }\end{array}$} \\
\hline & & Urbana & Rural & & & Urbana & Rural \\
\hline \multirow{2}{*}{ Faina } & Caiçara & 347 & 578 & \multirow{3}{*}{ Niquelândia } & $\begin{array}{l}\text { São Luiz } \\
\text { doTocantins }\end{array}$ & - & 2628 \\
\hline & Jeroaquara & 229 & 690 & & Tupiraçaba & 150 & 2034 \\
\hline \multirow[b]{2}{*}{ Faz. Nova } & Bacilândia & 399 & 457 & & Vila Taveira & 1151 & 1459 \\
\hline & Serra Dourada & 132 & 232 & Nova Crixás & Bandeirantes & 1023 & 2455 \\
\hline \multirow{3}{*}{ Formosa } & Bezerra & 1741 & 1047 & Orizona & Alto Alvorada & 135 & 807 \\
\hline & \begin{tabular}{|l|} 
Juscelino \\
Kubitschek
\end{tabular} & 1144 & 565 & Pirenópolis & Lagolândia & 205 & 718 \\
\hline & Santa Rosa & 852 & 2173 & \multirow[b]{2}{*}{ Planaltina } & Córrego Rico & 214 & 1074 \\
\hline Goianésia & Natinópolis & 182 & 109 & & $\begin{array}{l}\text { São Gabriel de } \\
\text { Goiás }\end{array}$ & 1082 & 2979 \\
\hline \multirow{5}{*}{ Goiás } & Buenolândia & 85 & 867 & Rialma & Castrinópolis & 90 & 307 \\
\hline & Calcilândia & 228 & 1260 & \multirow{3}{*}{ Rio Verde } & $\begin{array}{l}\text { Lagoa do } \\
\text { Bauzinho }\end{array}$ & 1234 & 495 \\
\hline & Davidópolis & 1404 & 534 & & Ouroana & 771 & 203 \\
\hline & São João & 208 & 290 & & Riverlândia & 735 & 250 \\
\hline & Uvá & 301 & 1600 & Rubiataba & Valdelândia & 195 & 374 \\
\hline Goiatuba & Marcianópolis & 744 & 451 & $\begin{array}{l}\text { São João } \\
\text { d'Aliança }\end{array}$ & Forte & 140 & 1874 \\
\hline \multirow[b]{2}{*}{ Ipameri } & Cavalheiro & 92 & 341 & $\begin{array}{l}\text { São Luís de } \\
\text { Montes Belos }\end{array}$ & Rosalândia & 252 & 926 \\
\hline & \begin{tabular}{|l|} 
Domiciano \\
Ribeiro \\
\end{tabular} & 3164 & 583 & São Simão & Itaguaçu & 1339 & 576 \\
\hline Israelândia & Piloândia & 141 & 96 & \multirow{2}{*}{ Uruaçu } & Geriaçu & 48 & 359 \\
\hline Itapaci & Ap. de Goiás & 80 & 239 & & Pau Terra & - & 570 \\
\hline Itapirapuã & Jacilândia & 487 & 714 & \multirow{2}{*}{ Uruana } & Uruceres & 408 & 200 \\
\hline \multirow{2}{*}{ Itapuranga } & Cibele & 179 & 348 & & Uruíta & 904 & 574 \\
\hline & Diolândia & 537 & 265 & Vianópolis & Caraíba & 215 & 453 \\
\hline
\end{tabular}

Fonte: Elaborada pelos autores, com dados do IBGE (2011).

A terceira situação mostra que, se por um lado há distritos com população acima de mil habitantes, a exemplo de Uruíta (município de Uruana) e Marcianópolis (município de Goiatuba), por outro lado, há os que não alcançam sequer a marca de 500 habitantes, como é o caso de Geriaçu (município de Uruaçu) e Valdelândia (município de Rubiataba). Os dados também mostram distritos com 100\% de população rural. O caso de Pau Terra está relacionado à divisão do município de Uruaçu após a emancipação de Campinorte. Mas, em outros casos, essa anomalia tem relação com a falta de definição do perímetro urbano, com o declínio populacional da vila - o que também explica a extinção de alguns distritos - e com o fato 
de que nem todas as vilas criadas pelas legislações municipais possuem ocupação urbana. Vale lembrar que, conforme apontado por Arrais (2013), o critério utilizado para a definição do que é urbano no Brasil deriva exclusivamente de uma normativa, o já mencionado Decreto-Lei no 311, de 1938.

Importa observar, também, que em 58\% dos distritos goianos a população rural é maior que a população urbana, como mostram os gráficos da Figura 1. Bandeirante, por exemplo, localizado no município de Nova Crixás, possui 70,5\% da população residindo na zona rural. Em Posse d'Abadia (município de Abadiânia), essa porcentagem é ainda maior, já que a população rural representa $87 \%$ da população total do distrito. Apesar dessa característica, alguns distritos já apresentam população urbana maior que a rural, como é o caso de Santo Antônio do Rio Verde (município de Catalão) e Juscelino Kubitschek (município de Formosa), que possuem, respectivamente, $61 \%$ e $67 \%$ de população urbana.

A Figura 1, além de evidenciar a população total, urbana e rural dos distritos goianos, mostra também a distância da sede distrital à sede municipal, assim como a população total de todos os municípios. A figura não apresenta os distritos de Nova Brasília e Jardim Ingá, por terem população muito acima da média dos distritos goianos (de muitas cidades também). Também, pelo fato de estarem localizados em contextos eminentemente metropolitanos e, portanto, por fugirem à regra dos distritos em Goiás.

Do ponto de vista da formação, grande parte dos distritos goianos tem sua gênese vinculada à fundação de povoados, muitos deles formados no contexto de atividades agropastoris. Extensas áreas, onde as práticas rudimentares de subsistência e comercialização de excedentes foram fundamentais para o crescimento econômico regional durante e após a exploração aurífera, as fazendas eram, não faz muito tempo, o espaço por excelência das atividades agropastoris que constituíram um dos principais fatores de povoamento e urbanização do território goiano, como analisado por Gomes, Teixeira Neto e Barbosa (2004) e Arrais (2013).

Acresce-se a isso as implicações do ímpeto político em direção ao interior do sertão brasileiro. A famosa campanha nacionalista Marcha para o Oeste (que teve como alguns de seus ícones a fundação de Goiânia em 1933 e a criação da Colônia Agrícola Nacional de Goiás em 1941) trouxe consigo os sentidos da modernização e processos que, consequentemente, alcançaram os lugares que hoje conhecemos por povoados e lugarejos, dando origem à criação dos distritos. 


\section{Distritos goianos: espacialização e população por tipo de residência (2010)}

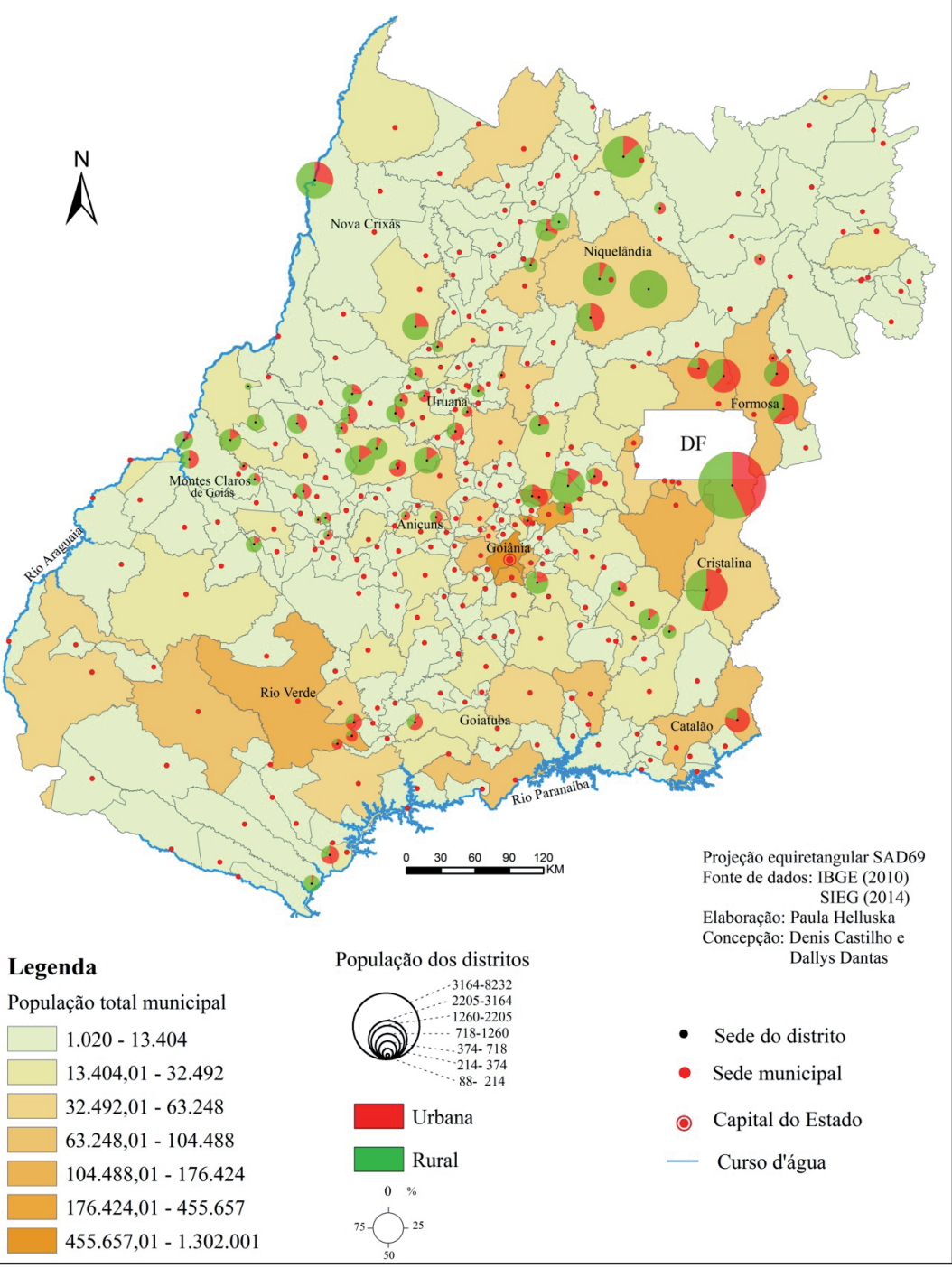

Figura 1 - Distritos goianos: espacialização e população por tipo de residência (2010) Fonte: Elaborada pelos autores, com base em IBGE (2010) e Goiás (2014). 
Entre outros fatores, esses sobrepuseram suas marcas às investidas dos bandeirantes, principalmente no que se refere às estradas (hoje rodovias), como defendem Gomes, Teixeira Neto e Barbosa (2004). As chamadas redes técnicas (rodovias, comunicações, eletricidade etc.), cada qual ao seu tempo, não obstante a concomitância, foram construídas progressivamente no território goiano, alterando o sentido de imensidão, distância e posicionamento, como defende Castilho $(2012,2014)$. Muitos aglomerados, nesse sentido, também têm sua gênese vinculada à implantação de redes de transportes, seja ao longo de rodovias, seja também da antiga Estrada de Ferro Goiás. Em síntese, o pano de fundo da genealogia de boa parcela desses distritos é a própria conjuntura socioeconômica e política do território goiano, especialmente nas primeiras décadas do século passado.

Isso explica, até certo ponto, a espacialização dos distritos em Goiás. Conforme pôde ser visto na Figura 1, grande parte dessas unidades concentra-se nas regiões centro e noroeste do estado, com destaque para os municípios de Anápolis, Goiás e Montes Claros de Goiás, que, juntos, somam 13 dos 71 distritos existentes. No centro de Goiás, como assinalam Faissol (1952), França (1985) e Teixeira Neto (2002), o processo de expansão da modernização, verificado a partir da década de 1930 na região anteriormente denominada Mato Grosso Goiano, ajuda a compreender a multiplicação de povoados e lugarejos. Essa região também é caracterizada por concentrar, além da Região Metropolitana de Goiânia e de cidades como Anápolis, uma significativa quantidade de cidades pequenas.

No noroeste goiano, a formação de pequenos núcleos decorre das atividades ligadas à agropecuária, bastante emblemática nessa região. No norte, também existem distritos localizados em municípios como Niquelândia, Uruaçu e Alto Paraíso de Goiás. Há ainda alguns distritos no leste de Goiás, como em Cristalina, Formosa, Luziânia e Planaltina, cuja urbanização foi intensificada em função da criação de Brasília na década de 1960. Por fim, ainda que de modo menos concentrado, o sul goiano também possui algumas unidades distritais pertencentes a municípios, como Catalão, Goiatuba, Rio Verde e São Simão.

Muitas localidades instituídas como distritos outrora foram povoados e/ou lugarejos. A partir do processo de povoamento do território goiano, cuja migração teve aumento nos anos de 1920 e 1940 (Gomes; Teixeira Neto; Barbosa, 2004), alguns lugarejos e povoados evoluíram demograficamente e tornaram-se núcleos urbanos relativamente impor- 
tantes para o período, pois começaram a concentrar fluxos de pessoas, principalmente do meio rural, em busca de bens de consumo e também atraídos pelos costumes religiosos: missas, novenas, batizados, romarias, folia de reis e festejos dedicados aos santos padroeiros dessas localidades. Em função do papel e da influência da Igreja Católica no período, muitos povoados têm sua gênese vinculada à construção de uma capela. Além disso, Gomes, Teixeira Neto e Barbosa (2004) ressaltam que algumas aglomerações surgiram como "patrimônios". Os autores explicam que,

em linguagem popular, mas que já se encontra incorporado à linguagem do geógrafo, "patrimônio" significa uma pequena aglomeração urbana em zona rural. Nesse sentido, é também chamado de "comércio" ou "rua". Trata-se, na verdade, de embriões de cidades surgidos em meio rural em decorrência de movimentos e fluxos espontâneos, ou dirigidos, de ocupação e organização do espaço. (p. 72)

Muitos desses "embriões", conforme afirmam os autores, de fato tornaram-se cidades, como é o caso de Santa Bárbara e Itapuranga. Outros, porém, estagnaram-se e hoje em dia não passam de lugarejos ou povoados. Há ainda as vilas que surgiram em decorrência das explorações auríferas, como Buenolândia (antiga Barra), e aquelas que se formaram em função de políticas de imigração, como Uvá, que se originou a partir de uma colônia de migrantes alemães no município de Goiás.

Apesar do papel dos distritos, tanto no processo de formação do território goiano como na sua atual composição socioespacial, alguns desafios são evidentes, especialmente no que se refere às funções que deveriam exercer do ponto de vista administrativo. Para ficarmos em alguns exemplos, muitos distritos carecem de ações efetivas no que diz respeito à prestação de serviços básicos, como assistência médica, educação escolar e saneamento básico. Monastiky et al. (2009) argumentam que o distrito parece ser a "escala esquecida". Em pesquisa sobre a realidade paranaense, os autores constataram que, muito embora a modernização agrícola tenha avançado e atingido determinadas "cidades do campo", os benefícios sociais desse processo modernizador não alcançaram as populações distritais. Também afirmam que a distância em relação às sedes municipais e a baixa densidade demográfica são fatores que dificultam "a formação de capital político nos distritos para barganhar por maior autonomia administrativa e atendimento as reivindicações da comunidade por melhor infraestrutura e serviços públicos” (Monastiky et al., 2009, p. 13). 
Os dados e as informações demonstram que a abordagem e a compreensão dos distritos exigem uma discussão dos condicionantes políticos, da atuação dos atores locais, da localização (se numa região com alta ou baixa densidade populacional), assim como do papel que a localidade exerce do ponto de vista dos serviços. Também é importante ressaltar as peculiaridades dos distritos, uma vez que variam conforme o período e a região em que estão inseridos.

\section{Peculiaridades dos distritos goianos}

A proximidade entre as pessoas, o trabalho e as atividades desenvolvidas no dia a dia são elementos que influenciam o cotidiano dos moradores de um distrito, residentes tanto no campo como na vila. Apesar de a sede distrital (a vila) ser definida legalmente como espaço urbano (e ainda que algumas de fato possuam infraestrutura, trabalho assalariado, oferta de serviços e equipamentos próximos ou acima da média de determinadas cidades pequenas), muitas assemelham-se mais a lugarejos com poucas residências do que, necessariamente, a efetivos núcleos urbanos. É comum, aliás, que grande parcela de residentes dessas vilas se ocupe de atividades rurais, caracterizando uma mobilidade diária de trabalhadores para o campo.

Dada a característica do pequeno número de consumidores, os distritos geralmente contam com poucos e pequenos estabelecimentos comerciais, a exemplo de mercado, padaria, farmácia, açougue, cabeleireiro, lanchonete etc. Em alguns é possível encontrar casas agropecuárias e produtos veterinários para atender à demanda de atividades agropastoris. Em geral, os estabelecimentos comerciais oferecem produtos e serviços que atendem às demandas básicas da pequena população. Por outro lado, serviços menos rotineiros, que exigem maior grau de qualificação e que geralmente são consumidos esporadicamente, dificilmente existem nas vilas.

É praticamente inimaginável encontrar, por exemplo, clínica ortopédica ou pet shop. A estrutura de serviços e a oferta de produtos, portanto, é bastante elementar e também influencia a mobilidade dos moradores em busca de serviços e produtos em cidades vizinhas, especialmente aquelas que exercem polarização na região. Isso contribui para a pouca circulação de capital nos distritos e coloca esses lugares em situação de dependência das cidades. É por isso que moradores de distritos se deslocam 
diariamente para uma cidade próxima em busca de serviços bancários, de saúde, educação, entre outros, contribuindo para a transferência de capital dos distritos para as cidades que os oferecem.

Conforme reconhece Arrais (2013, p. 117), há nas vilas e povoados goianos um rico "universo de símbolos e sociabilidade que envolve essas comunidades e suas relações de troca com as cidades”. Esses espaços possuem relações sociais que ao mesmo tempo permitem e impõem a necessidade de articulação com outras localidades, especialmente com as cidades, uma vez que nelas encontra-se a base material do consumo. No distrito, o trabalho, a renda, a necessidade e o desejo de consumir movem o sujeito em direção à cidade. Nela, o hospital, a escola, o supermercado, a agência bancária, a loja de roupas e calçados, entre outros estabelecimentos, são, portanto, os objetos mediadores desse processo.

Isso significa que, do ponto de vista da rede urbana, a dependência em relação à sede municipal e/ou às cidades mais próximas coloca a vila em posição inferior até mesmo aos centros urbanos que ocupam a posição mais elementar na hierarquia urbana do estudo desenvolvido pelo IBGE em 2008, intitulado "Região de Influência das Cidades" (REGIC). É importante advertir que muitas cidades pequenas, apesar de figurarem nas classificações do REGIC, exercem funções muito próximas ou tão elementares como as de uma vila. Por outro lado, também é necessário considerar que algumas vilas desempenham importantes papéis em seu entorno imediato, especialmente em localidades com proeminência de atividades rurais, sem, no entanto, contar com uma cidade próxima para atender às suas demandas. Como bem assinalado por Becker (1985), as vilas possuem um papel relevante na circulação de pessoas e de mercadorias.

A paisagem de um distrito, portanto, apesar de simples, contém vida e toda uma dinâmica que não pode ser negligenciada. O baixo número de ruas e residências, a incipiente rede de transporte, formada principalmente por estradas vicinais, a infraestrutura quase inexistente na maioria dos distritos, o tempo lento, entre outros, guardam relações e conflitos que não são claros em um primeiro momento. A realidade de cada vila ou povoado, portanto, não pode ser compreendida a partir de uma metodologia que geralmente se utiliza para compreender os espaços metropolitanos. É preciso considerar a formação do distrito, a sua participação na rede urbana, a vida de relações existentes na localidade e também a atuação dos atores sociais. Podemos citar, por exemplo, fazendeiros, camponeses, lideranças políticas, movimentos sociais, líderes religiosos 
e proprietários de estabelecimentos comerciais. O distrito, nesse sentido, não é isento de conflitos de interesses, o que lhe confere uma característica eminentemente política.

A dinâmica socioespacial de cada distrito também varia de região para região. Isso significa que a diversidade regional de Goiás deve ser considerada. Em todos os casos, a pouca circulação de capital e a posição inferior na rede urbana, como mencionado anteriormente, influenciam a pouca diversidade econômica do lugar e, consequentemente, outras características que são bastante comuns entre os distritos, a exemplo da estagnação, ou, em alguns casos, da perda populacional, como evidenciado pelos últimos censos do IBGE. Com exceção dos distritos de Vila Brasília e Jardim Ingá, os quais possuem população muito acima da média estadual, $60 \%$ dos distritos goianos registraram perda populacional entre os anos de 2000 e 2010 (IBGE, 2011). O total de habitantes dos distritos goianos nesse período (sem considerar Nova Brasília e Jardim Ingá) praticamente se manteve: 95.046 habitantes no censo de 2000 e 95.589 no de 2010.

A principal alteração ocorreu no quantitativo por tipo de residência. No ano de 2000, 62\% dos habitantes residiam nas áreas rurais dos distritos, e apenas 38\%, nas vilas. No ano de 2010, a população das vilas passou a representar $43 \%$ do total de habitantes, mas a maioria, $57 \%$, ainda permanece nas áreas rurais dos distritos. O aumento da população total dos distritos foi verificado em regiões próximas do eixo Goiânia Anápolis - Brasília, enquanto nas demais regiões houve perda populacional, especialmente nas áreas rurais dos distritos.

Isso significa que os distritos, junto com um significativo número de pequenas cidades, se constituem como exército de reserva, tal como assinalado por Corrêa (1999). Em função disso, uma parcela de seus habitantes migra para cidades que ocupam posições mais centralizadas na rede urbana, especialmente regiões metropolitanas, a exemplo de Brasília e Goiânia. Além disso, a ocupação de significativa parcela de trabalhadores geralmente é voltada às atividades agropastoris. E se as atividades do campo demandam, em sua maioria, o trabalho de pessoas do sexo masculino, é possível dizer que, dos migrantes que deixam os distritos, a maioria é de mulheres, que migram para cidades onde a oferta de emprego é mais diversificada. É por isso que a composição demográfica de distritos e pequenas cidades apresenta um número maior de habitantes do sexo masculino. Outra realidade é encontrada em cidades polos ou em regiões metropolitanas, onde a população feminina tende a ser maior. 
O cotidiano dos distritos, nesse sentido, é permeado por demandas bastante comuns nos espaços rurais. Muitos moradores são camponeses ou mesmo trabalhadores rurais, meeiros, arrendatários, lavradores, peões, vaqueiros, tropeiros etc. Marques (2013) defende que há nos povoados situações de intensa fluidez entre elementos urbanos e rurais. Práticas marcantes, como a religiosidade e a forte ligação com a terra, podem ser explicadas pela origem rural de muitos moradores, assegura a autora.

Silva (2008) também defende que as vilas, apesar de carregarem a nomenclatura oficial que as classifica como urbanas, carregam um conteúdo eminentemente rural. A preponderância do modo de vida em uma vila, contudo, tem relação com o contexto regional. Se existem distritos onde as práticas rurais e os costumes tradicionais são bastante evidentes, há também aqueles localizados próximos a centros importantes em que a população apresenta um comportamento mais atrelado à lógica urbana, haja vista o trabalho assalariado na indústria ou no comércio da cidade próxima. Além do mais, em alguns distritos o trabalho assalariado é verificado na própria vila, como em Lua Nova (município de Matrinchã), que possui estabelecimento para costura de peças de roupas da famosa marca Hering.

Outro dado importante é a porcentagem de aposentados dos distritos, que é superior à média do estado. Em São João, por exemplo, distrito do município de Goiás, os aposentados representam 20\% da população, enquanto no estado de Goiás são apenas 3,15\% da população total. Somado aos pensionistas, o número de inativos não passa de $12,5 \%$ em todo o estado (IBGE, 2011). Isso demonstra que o montante de capital repassado por meio de aposentadorias desempenha importante papel na dinâmica socioeconômica dos distritos.

Além da significativa porcentagem de aposentados, nos distritos também há servidores públicos, como professores, enfermeiros, policiais; agrônomos e veterinários, que geralmente prestam serviços para fazendas da região; pequenos comerciantes (açougueiro, cabeleireiro, padeiro, farmacêutico etc.) e freteiros, ${ }^{8}$ ou até mesmo migrantes pendulares, que se deslocam diariamente, em função do emprego, para a cidade vizinha. É também emblemática as figuras do barbeiro e do curandeiro ou benzedor. Esses sujeitos representam a forte ligação que as vilas mantêm com certas tradições. O cristianismo e as festas religiosas são casos ilustrativos e marcam o calendário festivo dos distritos - não é por acaso, aliás, que as igrejas e/ou capelas são elementos emblemáticos na paisagem dos distritos, como os de Uruíta (município de Uruana) e São João (município de Goiàs) (Figura 2). 

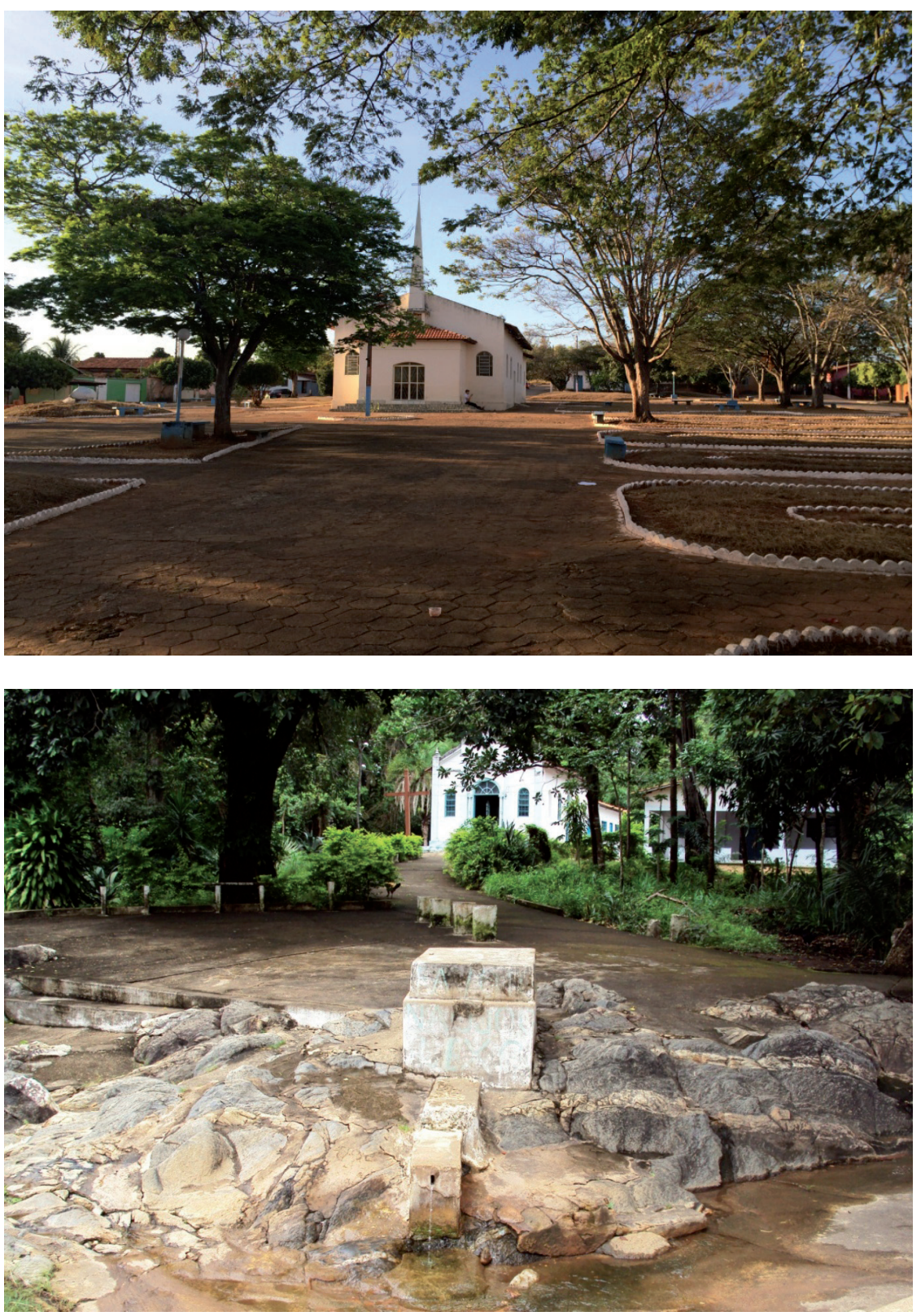

Figura 2 - Igreja Católica em Uruíta (Uruana) e São João (Goiás)

Fonte: Fotografias dos autores (2014) 
Apesar de os elementos apresentados neste trabalho (incluindo os dados demográficos) indicarem a forte ligação que muitos distritos goianos mantêm com as práticas rurais, é preciso considerar as transformações regionais em que estão inseridos, o tipo de vínculo dos sujeitos sociais com as atividades do campo e também com aquelas desenvolvidas em cidades vizinhas. Isso suscita uma discussão também do modo como elementos do fenômeno urbano são reproduzidos nesses lugares. Além disso, é preciso ultrapassar os critérios formais e compreender a formação do distrito, os processos internos, bem como aqueles que se estabelecem na relação com outras localidades.

\section{Para não finalizar}

Os distritos goianos apresentam uma variedade de realidades, em razão da própria diversidade territorial de Goiás. Mas, apesar da inexpressividade populacional, esses lugares também compõem a realidade territorial não apenas de Goiás, como também de significativa parcela de localidades distribuídas pelo Brasil. Além dos apontamentos discutidos neste artigo, ressaltamos a necessária discussão sobre questões relacionadas ao trabalho e ao caráter político desses lugares. Não é por acaso, aliás, que líderes políticos aguardam pela emancipação de seus distritos, na expectativa de garantir repasses da União e um "espaço" para efetivação de seus interesses. Isso tem sido um problema no Brasil, porque a criação de muitos municípios (e também de distritos) seguem tendências eleitoreiras, interesses específicos, e não, necessariamente, demandas administrativas. Por isso, apesar de serem instituídos para fins administrativos, muitos distritos são criados de maneira aleatória, às vezes sem dispor de serviços básicos e obedecendo a interesses particulares. Em realidade, portanto, ter o distrito como categoria eminentemente administrativa ainda apresenta-se como desafio no Brasil.

Ademais, considerar um determinado distrito no contexto da rede urbana demanda investigar o tipo e a natureza da rede, a densidade populacional da região, as relações do local com outros espaços, bem como a vida de relações que se estabelecem na escala do próprio distrito. Cita-se, por exemplo, a proporção de aposentados, a estrutura fundiária e a presença do Estado por meio de alguns serviços básicos. Se em alguns distritos há serviços permanentes de saúde e educação, em outros a presença 
de médico é esporádica e em muitos a atuação de policiais é garantida somente em datas festivas. Também cabe ressaltar que os distritos variam no tempo e espaço, o que reforça a pertinência de análises que levem em consideração a formação, as relações e atuações dos atores sociais, assim como os conflitos que surgem dessas relações. A pauta de discussões é longa. Afinal, o tema é um campo aberto de estudo. Esperamos que as questões levantadas contribuam para o debate sobre unidades territoriais e lancem luz em algumas questões polêmicas, a exemplo das leituras que definem as vilas (e também os povoados e lugarejos) como lugares desprovidos de conflitos. A vida que se desenvolve nesses lugares, entretanto, evidencia outra realidade.

\section{Notas}

1. O Distrito Federal é, assim como os estados e municípios, um ente federativo. Tem autonomia política, administrativa, financeira etc., e possui governo próprio. Localiza-se na região denominada Planalto Central e sua extensão territorial é de 5.779,999 $\mathrm{km}^{2}$. É também a unidade territorial sede do Governo Federal, com suas entidades supremas dos poderes Executivo, Legislativo e Judiciário. Brasília é a sede distrital, logo, capital federal (IBGE, 2011).

2. O Distrito Estadual de Fernando de Noronha é um arquipélago formado por 21 ilhas e administrado pelo Estado de Pernambuco nos termos de sua Constituição. Localiza-se a nordeste da costa brasileira, distante aproximadamente 543 quilômetros de Recife (PE). É dirigido por um Administrador-Geral nomeado pelo Governador do Estado com autorização da Assembleia Legislativa; conta ainda com a atuação do Conselho Distrital, uma espécie de órgão com funções consultivas e de fiscalização, formado por sete conselheiros eleitos para um mandato de quatro anos (Pernambuco, 2014).

3. Pela Lei estadual $n^{0}$ 6.944, de 19 de junho de1968, é criado o distrito de São João, sendo o seu território anexado ao município de Goiás (IBGE, [s.d.]).

4. A Lei $n^{0}$ 8.029, de $1^{\circ}$ de dezembro de 1975, cria o distrito de Goialândia, no município de Anápolis (Goiás, 2014b).

5. A Lei $\mathrm{n}^{\circ}$ 8.017, de 27 de novembro de 1975, cria o distrito de Jacilândia, no município de Itapirapuã (Goiás, 2014b).

6. Redação acrescida pela Emenda Constitucional n ${ }^{\circ}$ 46, de 9 de setembro de 2010.

7. De acordo com o censo de 2010, além dos 71 distritos criados por leis, Goiás possui 172 povoados distribuídos em 107 municípios (IBGE 2011). Apenas o Centro Goiano concentra 66 desses povoados.

8. Pessoa que faz o transporte de objetos, pessoas, equipamentos, animais etc., mediante acordo previamente estabelecido entre o interessado. 


\section{Referências}

ARRAIS, T. A. A produção do território goiano: economia, urbanização, metropolização. Goiânia: Ed. UFG, 2013.

BECKER, B. K. Fronteira e urbanização repensadas. Revista Brasileira de Geografia, Rio de Janeiro, ano 47, n. 3/4, jul./dez. p. 357-371, 1985.

BRASIL. Região de influência das cidades 2007. Rio de Janeiro: IBGE, 2008.

. Câmara dos Deputados. Decreto-Lei n. 311/1938. Dispõe sobre a divisão territorial do país, e dá outras providências. Disponível em: <http://www2. camara.leg.br/legin/fed/declei/1930-1939/decreto-lei-311-2-marco-1938-351501publicacaooriginal-1-pe.html>. Acesso em: 9 abr. 2014.

CASTILHO, D. Estado e rede de transportes em Goiás-Brasil (1889-1950). Scripta Nova. Revista Electrónica de Geografía y Ciencias Sociales. Barcelona: Universidad de Barcelona, 1 de noviembre de 2012, v. XVI, n. 418 (67). Disponível em: <http:// www.ub.es/geocrit/sn/sn-418/sn-418-67.htm>. Acesso em: 10 abr. 2014.

. Modernização e redes técnicas em Goiás. Tese (Doutorado em Geografia). Instituto de Estudos Socioambientais, Universidade Federal de Goiás, Goiânia, 2014.

CORRÊA, R. L. Globalização e reestruturação da rede urbana: uma nota sobre as pequenas cidades. Revista Território, ano IV, n. 6, jan./jun., p. 43-53, 1999.

FAISSOL, S. O "Mato Grosso de Goiás". Rio de Janeiro: IBGE/Conselho Nacional de Geografia, 1952.

FRANÇA, M. de S. Terra, trabalho e história: a expansão agrícola no "Mato Grosso” de Goiás - 1930-1955. Tese (Doutorado em História Social). Faculdade de Filosofia, Letras e Ciências Humanas, Universidade de São Paulo, São Paulo, 1985.

GOIÁS (Estado). Secretaria de Estado da Casa Civil. Constituições do Estado de Goiás. Constituição Estadual de 1967. Goiânia, 2014a. Disponível em: <http:// www.sgc.goias.gov.br/upload/arquivos/2011-08/constituicao-1967.pdf $>$. Acesso em: 18 mar. 2014.

. Secretaria de Estado da Casa Civil. Criação dos municípios de Goiás. Goiânia, 2014b. Disponível em: <http://www.casacivil.go.gov.br/post/ver/155258/ criacao-dos-municipios >. Acesso em: 18 mar. 2014.

. Constituições do Estado de Goiás. Emenda n. 1 à Constituição do Estado de Goiás. Goiânia, 2014c. Disponível em: <http://www.sgc.goias.gov.br/upload/ arquivos/2011-08/emenda-no.-1-a-constituicao-do-estado-de-goias-de-1967.pdf>. Acesso em: 18 mar. 2014.

GOMES, H.; TEIXEIRA NETO, A.; BARBOSA, A. S. Geografia: Goiás-Tocantins. 2. ed. rev. e ampl. Goiânia: Ed. UFG, 2004.

HOUAISS, A.; VILLAR, M. S. Dicionário Houaiss da língua portuguesa. Rio de Janeiro: Objetiva, 2001. 
IBGE. Instituto Brasileiro de Geografia e Estatística. Histórico de Goiás-GO. Biblioteca Digital do IBGE. [s.d.] Disponível em: <http://biblioteca.ibge.gov.br/ visualizacao/dtbs/goias/goias.pdf>. Acesso em: 6 mar. 2014.

- Glossário dos termos genéricos dos nomes geográficos utilizados no mapeamento sistemático do Brasil. Rio de Janeiro: IBGE, 2010.

. Censo demográfico 2010. Características da população e dos domicílios resultado do universo. Rio de Janeiro: IBGE, 2011.

MARQUES, A. C. de O. Espaço e habitus no sertão goiano: o povoado de Pouso Alto. Dissertação (Mestrado em Geografia). Instituto de Estudos Socioambientais, Universidade Federal de Goiás, Goiânia, 2013.

MONASTIKY, L. B.; ALBUQUERQUE, E. S. de; BAUCHROWITZ, L.; LIMA, J. de A. "Escala esquecida”: modernização e políticas públicas nos distritos municipais. Temas \& Matizes, n. 16, p. 8-23, $2^{\circ}$ sem. 2009.

PENHA, Eli Alves. A criação do IBGE no contexto da centralização política do Estado Novo. Rio de Janeiro: IBGE/ Centro de Documentação e Disseminação de Informações, 1993. Disponível em: <http://biblioteca.ibge.gov.br/visualizacao/ monografias/GEBIS\%20-\%20RJ/ColecaoMemoriaInstitucional/04-A\%20 Criacao\%20do\%20IBGE.pdf>. Acesso em: 6 mar. 2014.

PERNAMBUCO (Estado). Lei de Acesso à Informação. DEFN - Distrito Estadual Fernando de Noronha. Recife, 2014. Disponível em: <http://www.lai.pe.gov.br/ web/defn/institucional>. Acesso em: 2 abr. 2014.

SILVA, R. L. B. R. Patrimônios: espaço e lugar - estudo das vilas de Cibele e Caiçara e seus conteúdos. Tese (Doutorado em Geografia). Faculdade de Filosofia, Letras e Ciências Humanas, Universidade de São Paulo, São Paulo, 2008.

TEIXEIRA NETO, A. O Território Goiano: formação e processo de povoamento e urbanização. In: ALMEIDA, M. G. de (Org.). Abordagens geográficas de Goiás: o natural e o social na contemporaneidade. Goiânia: IESA, 2002. p. 11-46.

Dallys Dantas de Souza - Possui graduação em Geografia pela Universidade Federal de Goiás. Atualmente é funcionário da Secretaria Municipal de Educação de Aparecida de Goiânia.

Denis Castilho - Possui Graduação e Mestrado em Geografia pela Universidade Federal de Goiás. É Doutor em Geografia pela mesma Universidade. Atualmente é professor adjunto do Instituto de Estudos Socioambientais da Universidade Federal de Goiás.

Recebido para publicação em 13 de setembro de 2014 Aceito para publicação em 28 de outubro de 2014 